\title{
HUBUNGAN SPIRITUALITAS DAN SENSITIVITAS MORAL MAHASISWA KEPERAWATAN
}

\author{
I Gede Nova Ariawan*, Putu Mega Krisnayanti, Putu Gede Putra Suastrawan, Ni Putu Emy \\ Darma Yanti \\ Program Studi Sarjana Keperawatan dan Profesi Ners, Fakultas Kedokteran, Universitas Udayana \\ *gedenovariawan@gmail.com
}

\begin{abstract}
ABSTRAK
Spiritualitas sebagai sebuah keyakinan seringkali dikaitkan dengan hubungan transenden yang berdampak pada sikap dan perilaku individu, salah satunya sensitivitas moral dalam keperawatan. Sensitivitias moral merupakan ketentuan penting dalam praktik keperawatan dan menjadi tuntutan dalam memberikan pelayanan kesehatan secara holistik. Tujuan penelitian ini untuk mengidentifikasi hubungan spiritualitas dan sensitivitas moral mahasiswa keperawatan di Provinsi Bali. Penelitian kuantitatif dengan rancangan deskriptif korelasional ini mengikutsertakan 122 mahasiswa keperawatan di Bali sebagai sampel dan menggunakan teknik purposive sampling. Data dikumpulkan dengan menggunakan kuesioner data demografi, spiritualitas, dan sensitivitas moral. Penelitian ini memperoleh hasil bahwa terdapat hubungan antara spiritualitas dengan sensitvitas moral mahasiswa keperawatan di Provinsi Bali $(\mathrm{r}=0.320, P<0,001)$. Hasil ini menunjukkan bahwa adanya hubungan yang lemah antara kedua variabel dengan arah hubungan yang positif dengan makna semakin tinggi tingkat spiritualitas mahasiswa keperawatan maka semakin tinggi sensitivitas moral mahasiswa keperawatan. Faktor-faktor lain yang dapat memengaruhi sensitivitas moral mahasiswa keperawatan perlu diteliti lebih lanjut.
\end{abstract}

Kata kunci: spiritualitas, sensitivitas, moral, keperawatan

\section{SPIRITUALITY RELATIONSHIP AND MORAL SENSITIVITY OF NURSING STUDENTS}

\begin{abstract}
Spirituality as a belief is often associated with transcendent relationships that have an impact on individual attitudes and behavior, one of which is moral sensitivity in nursing. Moral sensitivity is an important provision in nursing practice and is a demand in providing health services holistically. The purpose of this study was to identify the relationship between spirituality and moral sensitivity of nursing students in Bali Province. This quantitative research with a descriptive correlational design included 122 nursing students in Bali as samples and used purposive sampling technique. Data was collected using demographic, spirituality and moral sensitivity data questionnaires. This study found that there was a relationship between spirituality and moral sensitivity of nursing students in Bali Province $(r=0.320, P<0.001)$. These results indicate that there is a weak relationship between both of variables with the direction of a positive relationship which means that the higher level of spirituality of nursing students then the higher level of moral sensitivity among nursing students. Other factors that can influence the moral sensitivity of nursing students need to be investigated further.
\end{abstract}

Keywords: spirituality, sensitivity, morality, nursing

\section{PENDAHULUAN}

Keperawatan merupakan bagian integral dari layanan kesehatan profesional yang berbasis ilmu dan kiat perawat, yang berbentuk layanan bio-psiko-sosio-spiritual (Widodo, Wungow, \& Hamel, 2016). Dari tahun ke tahun banyak terjadi perubahan-perubahan yang cukup signifikan dalam sistem keperawatan di dunia maupun di Indonesia seperti kemajuan teknologi, alat dan teknik, serta perawatan dan intervensi (Range \& Rotherham, 2010). Seiring dengan perubahan ini menjadikan kesadaran akan hak pasien tentunya meningkat 
namun hal yang sangat penting adalah spiritualitas dan moral.

Setiap perawat sering kali kurang sensitif mengenai pentingnya moral ketika melakukan asuhan keperawatan dikarenakan berbagai alasan. Kesulitan moral adalah fenomena yang sering terjadi dalam keperawatan, yang dapat menimbulkan paradoks dalam keperawatan serta mempengaruhi pelayanan keperawatan yang berkualitas tinggi. Sebagian besar penelitian etika dan moral keperawatan selama dekade terakhir menunjukan bahwa perawat tidak sepenuhnya siap untuk memberikan pelayanan keperawatan yang terbaik atau belum dapat berkontribusi secara tepat kepada pasien mereka (Woods, Rodgers, Towers, \& La Grow, 2015). Fenomena ini dapat menghambat tujuan dari keperawatan sehingga akan mempengaruhi standar kesehatan sosial di masyarakat (Hunt, 1997).

Peningkatan ilmu pengetahuan dan teknologi yang semakin pesat serta meningkatnya pengetahuan di lingkungan masyarakat sangat memengaruhi berbagai tuntutan masyarakat akan mutu pelayanan kesehatan termasuk pelayanan keperawatan. Hal ini merupakan tantangan bagi profesi keperawatan dalam meningkatkan sikap profesionalisme dalam memberikan asuhan keperawatan yang berkualitas. Kualitas pelayanan yang tinggi memerlukan landasan komitmen yang kuat berbasis pada etik serta moral yang tinggi (Boonyamanee, Suttharangsee, Chaowalit, \& Parker, 2014). Kemajuan ilmu kesehatan dan teknologi telah menyebabkan perubahan besar dalam praktik keperawatan dengan demikian perawat yang merawat pasien akan semakin rumit menyadari pentingnya pengambilan keputusan dalam praktik etis keperawatan. Upaya untuk meningkatkan sensitivitas moral dalam praktik keperawatan diintensifkan untuk mempersiapkan perawat agar lebih kompeten secara etis dalam melakukan asuhan keperawatan serta mengambil keputusan (Ohnishi et al., 2018). Tekanan moral menjadi salah satu faktor penyebab dari kurang sensitifnya perawat terhadap moralitas ketika melakukan praktik keperawatan (Lützén \& Ewalds-Kvist, 2013).

Berdasarkan penelitian Range et al, (2010) menunjukkan tingkat kepekaan moral rata-rata perawat adalah $68,6 \pm 7,8$, yang menunjukkan tingkat sensitivitas moral moderat. Di sisi lain, perawat juga mengalami tingkat tekanan moral moderat $(44,8 \pm 16,6)$. Salah satu faktor yang mempengaruhi sensitivitas moral yaitu spiritualitas yang menjadikan landasan penting dalam penerapan karakter setiap individu. Berdasarkan pemaparan di atas, peneliti bertujuan untuk mengidentifikasi hubungan antara spiritualitas dan sensitivitas moral mahasiswa keperawatan di Provinsi Bali dengan menggunakan pendekatan kuantitatif.

\section{METODE}

Penelitian ini menggunakan pendekatan kuantitatif dengan rancangan deskriptif korelasi secara cross sectional. Populasi pada penelitian ini adalah seluruh mahasiswa keperawatan di Provinsi Bali. Sampel pada penelitian ini diambil dari institusi pendidikan keperawatan di Provinsi Bali. Penelitian ini dilaksanakan di Institusi pendidikan keperawatan di Bali pada Juli hingga Desember 2018. Pengambilan sampel dilakukan melalui teknik non-probability sampling dengan purposive sampling berjumlah 122 mahasiswa, dengan kriteria inklusi : 1) Mahasiswa keperawatan program reguler, 2) Tidak sedang berada dalam masa cuti kuliah pada saat keseluruhan proses penelitian dilakukan (menikah, melahirkan, ataupun sakit), 3) Bersedia menjadi responden yang dibuktikan dengan surat kesediaan untuk menjadi responden. Pengumpulan data dilakukan menggunakan dua kuesioner. Kuesioner sensitivitas moral dalam keperawatan yang diadopsi dari penelitian Park (2011), yang terdiri dari 27 pernyataan dengan masing-masing pernyataan dinilai menggunakan rentang 1 (sangat tidak setuju) sampai 7 (sangat setuju). Kuesioner spiritualitas dalam penelitian ini digunakan untuk mengukur tingkat spiritualitas mahasiswa, terdiri atas 20 pernyataan positif dan negatif yang diadopsi dari penelitian Hardt, Schultz, Xander, Becker, dan Dragan, (2012). Kriteria pengukuran menggunakan skala likert untuk pernyataan positif; SS $($ Sangat Setuju $)=4$, S $($ Setuju $)=3$, TS $($ Tidak Setuju $)=2$, STS $($ Sangat Tidak Setuju $)=1$, sedangkan pernyataan negatif : $\mathrm{STS}=4, \mathrm{TS}=$ $3, \mathrm{~S}=2, \mathrm{SS}=1$. Analisis data menggunakan analisis univariat dan analisis bivariat. Penelitian ini telah disetujui oleh Komisi Etik 
$\begin{array}{lrr}\text { Penelitian Fakultas } & \text { Kedokteran } & \text { Universitas } \\ \text { Udayana/RSUP } & \text { Sanglah } & \text { No. } \\ \text { 2524/UN14.2.2.VII.14/LP/2018. } & \end{array}$

\section{HASIL}

Hasil penelitian ini menunjukkan bahwa sebagian besar responden berjenis kelamin perempuan $(68,9 \%)$ dan sebanyak $88,5 \%$ sudah pernah menjalankan praktik klinik, serta $79,5 \%$ merupakan mahasiswa keperawatan semester 5. Responden yang berpartisipasi dalam penelitian ini memiliki rata-rata usia 20 tahun dan jumlah saudara 3 orang. Selain itu, mayoritas responden dalam penelitian ini beragama Hindu yakni 115 orang $(94,3 \%)$ dan responden lainnya beragama Islam $(2,5 \%)$, Kristen (2,5\%), Katolik (0,8\%), lebih rinci dapat digambarkan pada tabel.
Skor rata-rata dan standar deviasi spiritualitas serta sensitivitas moral mahasiswa keperawatan secara berturut-turut 67,11 (SD = 5,383) dan 153,18 ( $\mathrm{SD}=15,33)$. Hasil tersebut menunjukkan bahwa $69(56,6 \%)$ mahasiswa keperawatan di Bali memiliki tingkat spiritualitas yang baik dan tidak ada perbedaan tingkat sensitivitas moral mahasiswa keperawatan. Hasil penelitian ini menunjukkan bahwa terdapat hubungan antara variabel spiritualitas dan sensitivitas moral mahasiswa di institusi pendidikan keperawatan di Bali dengan nilai $\mathrm{P}<0,001(\alpha=0,05)$. Kekuatan hubungan termasuk dalam kategori lemah $(\mathrm{r}=$ 0,320) dan arah hubungan positif yang bermakna semakin tinggi nilai spiritualitas, maka semakin tinggi sensitivitas moral mahasiswa keperawatan.

Tabel 1.

Karakteristik responden, rata-rata skor spiritualitas dan sensitivitas moral, kategori spiritualitas dan sensitivitas moral, dan analisis bivariat spiritualitas dan sensitivitas moral pada mahasiswa

keperawatan $(\mathrm{n}=122)$

\begin{tabular}{|c|c|c|c|c|c|c|}
\hline Variabel & $\mathrm{f}$ & $\%$ & Median & Mean (SD) & Min-Max & $95 \% \mathrm{CI}$ \\
\hline \multicolumn{7}{|c|}{ Distribusi karakteristik responden } \\
\hline \multicolumn{7}{|c|}{ Jenis kelamin } \\
\hline Laki-laki & 38 & 31,1 & - & - & - & - \\
\hline Perempuan & 84 & 68,9 & & & & \\
\hline \multicolumn{7}{|l|}{ Pengalaman praktik } \\
\hline Pernah & 108 & 88,5 & - & - & - & - \\
\hline Tidak perah & 14 & 11,5 & & & & \\
\hline \multicolumn{7}{|l|}{ Semester } \\
\hline 1 & 12 & 9,8 & & & & \\
\hline 3 & 13 & 10,7 & - & - & - & - \\
\hline 5 & 97 & 79,5 & & & & \\
\hline \multicolumn{7}{|l|}{ Agama } \\
\hline Hindu & 115 & 94,3 & & & & \\
\hline Islam & 3 & 2,5 & - & - & - & - \\
\hline Kristen & 3 & 2,5 & & & & \\
\hline Katolik & 1 & 0,8 & & & & \\
\hline Usia (tahun) & - & - & 20 & - & $17-22$ & $19,85-20,17$ \\
\hline Jumlah saudara & - & - & 3 & - & $0-8$ & $2,5-3,01$ \\
\hline \multicolumn{7}{|c|}{ Rata-rata skor spiritualitas dan sensitivitas moral } \\
\hline Spiritualitas & - & - & - & $67,11(5,383)$ & - & $66,14-68,07$ \\
\hline Sensitivitas moral & - & - & - & $153,18(15,33)$ & - & $150,43-155,93$ \\
\hline \multicolumn{7}{|c|}{ Kategori spiritualitas dan sensitivitas moral } \\
\hline \multicolumn{7}{|c|}{ Spiritualitas } \\
\hline Kurang & 53 & 43,4 & - & - & - & - \\
\hline Baik & 69 & 56,6 & & & & \\
\hline \multicolumn{7}{|l|}{ Sensitivitas moral } \\
\hline Kurang & 61 & 50 & - & - & - & - \\
\hline Baik & 61 & 50 & & & & \\
\hline \multicolumn{7}{|c|}{ Analisis bivariat spiritualitas dan sensitivitas moral } \\
\hline Variabel & \multicolumn{6}{|c|}{ Sensitivitas Moral } \\
\hline \multirow{2}{*}{ Spiritualitas } & & & $\mathrm{R}$ & & & \\
\hline & & & 0,320 & & & \\
\hline
\end{tabular}




\section{PEMBAHASAN}

Hasil penelitian ini mendapatkan hasil bahwa sebagian besar dari mahasiswa memiliki tingkat spiritualitas yang baik $(56,6 \%)$. Pernyataan ini diperkuat oleh penelitian Dalam penelitian (Borhani, Abbaszadeh, \& Mohsenpour, 2013) menyebutkan "Faith in God is very important", ucap participan. "Unfortunately, we will not go to patients' beside anymore when we are in charge of the shift. In such situations, I wonder if my salary is halal. A lot of other nurses may think about the same things. I always think that even if I do not give a vitamin pill to the patient, I'll owe him/her". Hasil tersebut bermakna spiritualias sangat memengaruhi kesetiaan dan sensitivitas moral terhadap pasien karena memengaruhi emosi dan empati kepada pasien nantinya.

Skor rata-rata sensitivitas moral mahasiswa keperawatan di Bali, yakni 153,18 dengan standar deviasi mencapai 15,33 dan kategori sensitivitas moral berbanding 50:50 antara kategori baik dan kurang. Hasil tersebut menunjukkan, masih rendahnya kesadaran mahasiswa keperawatan mengenai pentingnya sensitivitas moral dalam memberikan perawatan dan menjalankan tugasnya sebagai profesional. Hasil tersebut didukung dengan hasil studi yang meneliti pentingnya kepekaan moral (sensitivitas moral) dalam perawataan pasien dengan dimensia. Penelitian tersebut menyatakan bahwa perhatian penuh dan kepekaan secara moral akan menjalin hubungan yang baik antara pasien dan perawat (Heggestad, Nortvedt, \& Slettebø, 2013). Penelitian lain juga menyatakan bahwa sensitivitas etis dalam mengembangkan penilaian moral dan temuan ini penting sebagai pembelajaran etik (Jagger, 2011). Studi lain juga menunjukkan bahwa moral distress yang dialami perawat dapat berdampak pada pelayanan yang diberikan, meliputi perawatan berkualitas buruk, advokasi yang tidak berhasil, dan harapan yang tidak realistis (Schluter, Winch, Holzhauser, \& Henderson, 2008). Hasil studi lainnya juga menyatakan bahwa sebagian besar mahasiswa keperawatan pada area klinis mengalami situasi yang secara moral menyedihkan dan berdampak pada kualitas perawatan pasien (Escolar-Chua, 2018).
Penelitian ini memperoleh hasil bahwa ada hubungan antara variabel spiritualitas dan sensitivitas moral mahasiswa di institusi pendidikan keperawatan di Bali ( $\mathrm{r}=0,320$, $P<0.001)$ dengan arah hubungan positif bermakna semakin tinggi nilai spiritualitas, maka semakin tinggi sensitivitas moral mahasiswa keperawatan. Arsang-Jang, Khoramirad, Pourmarzi, dan Raisi (2017) menyatakan bahwa perawat yang memiliki tingkat spirituality intelligent tinggi akan berusaha untuk memikirkan dan mempertimbangkan pemikiran berprinsip (principled thinking) lebih banyak terkait prinsip dalam memutuskan etik. Peneliti berpendapat bahwa pemahaman mahasiswa tentang spiritualias akan berdampak pada sensitivitas moral seperti menghargai pasien, memenuhi kebutuhan spiritual dan agama pasien serta menghargai privasi klien.

Adanya hubungan dengan kategori lemah ( $\mathrm{r}=$ 0,320) antara spiritualitas dan sensitivitas moral mahasiswa keperawatan di Provinsi Bali dapat dipengaruhi oleh beberapa faktor lain, selain faktor spiritualitas mahasiswa keperawatan. Hasil tersebut dipengaruhi oleh penelitian sebelumnya yang meneliti pengalaman mahasiswa keperawatan terhadap faktor yang efektif mempengaruhi sensitivitas etik, yakni karakteristik individu dan spiritual, pendidikan, saling memahami (mutual understanding), pengawasan internal dan eksternal, serta pengalaman tindakan yang tidak sopan (Borhani et al., 2013). Penelitian lain juga menyatakan bahwa pengetahuan perawat mengenai etik keperawatan, karakteristik pekerjaan, dan pengawasan dari manajer keperawatan menjadi faktor yang mempengaruhi penerapan prinsip etik keperawatan (Kim, Kang, \& Ahn, 2013; Yanti, Handiyani, \& Kuntarti, 2017). Studi sebelumnya yang meneliti hubungan pendidikan etik terhadap sensitivitas moral dan kemampuan moral reasoning mahasiswa keperawatan memperoleh hasil positif, yakni terdapat hubungan antara tingkat akademik terhadap sensitivitas moral khususnya dimensi patient-oriented care $(p<0,001)$ dan conflict $(p<0,05)$. Penelitian ini membagi dimensi sensitivitas moral menjadi lima, meliputi patient-oriented care, professional responsibility, conflict, meaning, dan benevolence (Park, Kjervik, Crandell, \& 
Oermann, 2012). Faktor lain yang dapat memengaruhi sensitivitas moral ialah selfesteem, semakin tinggi tingkat self-esteem tentunya semakin tinggi sensitivitas moral perawat tersebut. Studi yang dilakukan oleh (Rahnama, Mardani-Hamooleh, \& Kouhnavard, 2017) tersebut menjelaskan bahwa sebagian besar tingkat sensitivitas moral dan self-esteem berada pada tingkat moderat $(61,2 \%)$. Hasil studi lain menyatakan bahwa terdapat hubungan data demografi dengan moral distress menunjukkan hasil yang signifikan antara lain usia, pendidikan, departemen, pengalaman bekerja, posisi, pekerjaan, dan pendapatan perbulan dan memperoleh tidak ada hubungan antara jenis kelamin dan status pernikahan dengan moral distress (Wenwen, Xiaoyan, Yufang, Lifeng, \& Congcong, 2018).

Penelitian ini mendapatkan hasil bahwa sensitivitas moral mahasiswa keperawatan di Bali yaitu sebanding antara hasil kurang baik dan baik untuk tingkat sensitivitasnya. Hal ini karena dipengaruhi oleh beberapa faktor selain spiritualitas. Sehingga diperlukan upaya untuk meningkatkan sensitivitas moral seperti diperlukan adanya pelatihan, melakukan konsultasi secara periodik, dan membuat persetujuan untuk kesanggupan dalam bekerja, hal ini dapat secara efektif membantu mengatur situasi stres dan dapat memberikan perawat kesempatan untuk bekerja dengan membatasi lingkungan tekanan moral. Dalam penelitian yang dilakukan oleh Rahnama et al. (2017) dijelaskan bahwa penerapan intervensi edukasi psikologi juga dapat dilakukan untuk meningkatkan harga diri perawat, dan hasil penelitianya menyebutkan bahwa latihan khusus untuk mempromosikan sensitivitas moral dan harga diri perawat dapat meningkatkan pemberdayaan moral dan psikologis. Penelitian oleh Schluter et al. (2008) menyebutkan bahwa sangat penting dilakukan untuk mengembangkan kepekaan moral perawat melalui berbagai program pelatihan dan pendidikan. Pemberian pendidikan disarankan lebih mengidentifikasi tingkat sensitivitas individu pada tahap awal seperti melalui latihan debat berbasis kelompok mengenai masalah etika (seperti wawancara dengan korban kejahatan) yang akan membantu membangun empati. Pendidikan komunikasi, kerjasama, dan teknik keterampilan melalui bermain "game" berguna untuk mengembangkan sensitivitas moral perawat untuk lebih sensitif terhadap masalah etika di lingkungn profesional perawat (Maddineshat, Yousufzadeh, Mohseni, \& Maghsoudi, 2019).

\section{SIMPULAN}

Ada hubungan antara spiritualitas dengan sensitivitas moral pada mahasiswa keperawatan di Bali dengan kekuatan hubungan yang lemah dan arah hubungan bernilai positif. Mahasiswa keperawatan di Bali memiliki spiritualitas yang baik.

\section{DAFTAR PUSTAKA}

Arsang-Jang, S., Khoramirad, A., Pourmarzi, D., \& Raisi, M. (2017). Relationship Between Spiritual Intelligence and Ethical Decision Making in Iranian Nurses. Journal of Humanistic Psychology, $\quad 002216781770431$. https://doi.org/10.1177/0022167817704 319

Boonyamanee, B., Suttharangsee, W., Chaowalit, A., \& Parker, M. E. (2014). Exploring moral sensitivity among Thai psychiatric nurses. 34, 9.

Borhani, F., Abbaszadeh, A., \& Mohsenpour, M. (2013). Nursing students' understanding of factors influencing. Iranian Journal of Nursing and Midwifery Research, 18(4), 6.

Escolar-Chua, R. L. (2018). Moral sensitivity, moral distress, and moral courage among baccalaureate Filipino nursing students. Nursing Ethics, 25(4), 458469.

https://doi.org/10.1177/0969733016654 317

Hardt, J., Schultz, S., Xander, C., Becker, G., \& Dragan, M. (2012). The Spirituality Questionnaire: Core Dimensions of Spirituality. Psychology, 03(01), 116122.

https://doi.org/10.4236/psych.2012.3101 7

Heggestad, A. K. T., Nortvedt, P., \& Sletteb $\varnothing$, $\AA$. (2013). The importance of moral sensitivity when including persons with 
dementia in qualitative research. Nursing Ethics, 20(1), 30-40. https://doi.org/10.1177/0969733012455 564

Hunt, G. (1997). Moral crisis, professionals and ethical education. Nursing Ethics, 10 .

Jagger, S. (2011). Ethical sensitivity: A foundation for moral judgment. Journal of Business Ethics Education, 8(1), 1330 .

Kim, Y.-S., Kang, S.-W., \& Ahn, J.-A. (2013). Moral sensitivity relating to the application of the code of ethics. Nursing Ethics, 20(4), 470-478. https://doi.org/10.1177/0969733012455 563

Lützén, K., \& Ewalds-Kvist, B. (2013). Moral Distress and its Interconnection with Moral Sensitivity and Moral Resilience: Viewed from the Philosophy of Viktor E. Frankl. Journal of Bioethical Inquiry, 10(3), 317-324. https://doi.org/10.1007/s11673-0139469-0

Maddineshat, M., Yousufzadeh, M. R., Mohseni, M., \& Maghsoudi, Z. (2019). Teaching ethics using games: Impact on Iranian nursing students' moral sensitivity. Indian Journal of Medical Ethics, IV(1), 14-20. https://doi.org/10.20529/IJME.2018.056

Ohnishi, K., Kitaoka, K., Nakahara, J., Välimäki, M., Kontio, R., \& Anttila, M. (2018). Impact of moral sensitivity on moral distress among psychiatric nurses. Nursing Ethics, 096973301775126. https://doi.org/10.1177/0969733017751 264

Park, M. (2011). The relationship of ethics education to moral sensitivity and moral reasoning of students in baccalaureate nursing programs of South Korea. 166.

Park, M., Kjervik, D., Crandell, J., \& Oermann, M. H. (2012). The relationship of ethics education to moral sensitivity and moral reasoning skills of nursing students. Nursing Ethics, 19(4),
568-580.

https://doi.org/10.1177/0969733011433 922

Rahnama, F., Mardani-Hamooleh, M., \& Kouhnavard, M. (2017). Correlation between moral sensitivity and selfesteem in nursing personnel. Journal of Medical Ethics and History of Medicine, 10. Retrieved from https://www.ncbi.nlm.nih.gov/pmc/articl es/PMC6150914/

Range, L. M., \& Rotherham, A. L. (2010). Moral distress among nursing and nonnursing students. Nursing Ethics, 17(2), 225-232. https://doi.org/10.1177/0969733009352 071

Schluter, J., Winch, S., Holzhauser, K., \& Henderson, A. (2008). Nurses' moral sensitivity and hospital ethical climate: a literature review. Nursing Ethics, 15(3), 304-321. https://doi.org/10.1177/0969733007088 357

Widodo, W. N., Wungow, H., \& Hamel, R. S. (2016). Hubungan peran ketua TIM dengan kinerja perawat pelaksana dalam pendokuemtasian asuhan keperawatan di IRINA F RSUP Prof Dr. R. D. Kandou Manado. JURNAL KEPERAWATAN, 4(2). $\quad$ Retrieved from https://ejournal.unsrat.ac.id/index.php/jk p/article/view/12871

Woods, M., Rodgers, V., Towers, A., \& La Grow, S. (2015). Researching moral distress among New Zealand nurses: A national survey. Nursing Ethics, 22(1), 117-130. https://doi.org/10.1177/0969733014542 679

Yanti, N. P. E. D., Handiyani, H., \& Kuntarti. (2017). The Determinants of ethical principle implementation in nursing. Journal of Health Sciences and Medicine, 1(2), 16-22. 